\title{
Teacher Moments: A digital clinical simulation platform with extensible AI architecture
}

\author{
Garron Hillaire ${ }^{1}$, Rick Waldron, Chas Murray², Ritam Dutt ${ }^{2}$, G. R. Marvez ${ }^{1}$, \\ Laura Larke ${ }^{1}$, Carolyn Rosé ${ }^{2}$, and Justin Reich ${ }^{1}$ \\ ${ }^{1}$ Massachusetts Institute of Technology, Cambridge MA 02139, USA \\ ${ }^{2}$ Carnegie Mellon University. Pittsburgh, PA 15213, USA
}

\section{Summary}

Teacher Moments ${ }^{1}$ is an open source platform that allows the authoring of simulations used for education [3] which we recently revised to integrate intelligent coaching agents. The initial simulation development for Teacher Moments focused on teacher education $[9,2,3]$, but the platform is actively used for professional development with nurses, psychologists, police officers, judges, and attorneys. Simulations can range in complexity from single-user simulations to multi-user role-play simulations [2]. Single-user simulations provide opportunities for participants to respond using text or audio inputs while multi-user simulations extend those response types to include chat functionality. To support participant learning, Teacher Moments simulations can now be configured to include intelligent coaching agents that review participant inputs, identify salient patterns in text or speech, and respond with feedback and coaching supports. Teacher Moments can be configured to incorporate text ${ }^{2}$ or audio ${ }^{3}$ binary classifiers or include conversational agents ${ }^{4}$ into the chat feature. Once a classifier is configured there is functionality to dynamically display content based on audio or text classification when authoring the simulation. In addition, conversational agents can interject comments into the chat directed at either a particular participant or to all participants in a chat. Finally, there is a new integrated labeling component that supports collecting binary labels from participants for text or audio data, which can be used either to validate the accuracy of a classifier or to establish training data for a classifier. In this demo, we will: 1) highlight GitHub repositories designed to support the deployment of classifiers that can be integrated into Teacher Moments; 2) demonstrate a conversational agent integrated into the chat feature to provide intelligent supports; 3) illustrate how binary classification can trigger the dynamic display of content providing options for dynamic learning supports; and 4) demonstrate how the labeling component can be used for either validation of a classifier or collection of training data.

\section{Impact}

Teacher Moments scenarios are integrated in several teacher professional development programs. They are incorporated in two massive open online courses 
for teachers about equity teaching practices [5] and information literacy [6]. They are used in a research-practice partnership with Grade 3-8 math teachers [1] to support more inclusive classrooms with richer math-related dialogue. In this interactive demonstration, we will share Teacher Moments scenarios from a program called Innovative New Spaces for Practice and Rehearsal in Teacher Education (INSPIRE) CS-AI.

We are currently supporting 22 teacher educator fellows in authoring, implementing (with their preservice teachers) and researching Teacher Moments simulations focused on issues of equity in K-12 computer science instruction. This focus was selected as K-12 CS teacher education programs are just starting to emerge in teacher preparation programs and injecting a focus on equity during these initial phases has the potential to shape how computer science is taught in K-12 classrooms. These 22 fellows implement simulations on average with 20 pre-service and current classroom teachers, which means roughly 440 in-/pre-service teachers will have opportunities to practice responding to issues of equity in K-12 CS classrooms as part of their teacher education programs and professional development training programs.

In addition to the 22 fellows focused on K-12 CS instruction there are around 50 additional educators at various stages of authoring and implementing Teacher Moments in a variety of contexts, but most frequently tackling issues of equity. We can outline the amount of data collected in Teacher Moments as an indicator of direct impact. At the point of writing this proposal, over 70 authors have created $400+$ simulations. Over $8 \mathrm{k}$ Teacher Moments simulation users have provided $32 \mathrm{k}+$ audio responses, $82 \mathrm{k}+$ text responses, and nearly $1 \mathrm{k}$ chat messages (a feature we released this month). For indirect impact, if only half of the $8 \mathrm{k}$ Teacher Moments participants eventually serve classrooms of roughly 20 K-12 students, this would indirectly impact roughly $80 \mathrm{k} \mathrm{K}-12$ students $\left(20^{*} 4 \mathrm{k}\right)$.

\section{Relevance}

The Teacher Moments platform supports distributed authorship allowing educators to author, implement, and research equity-focused simulations [3, 4]. Equity issues explored include: trauma informed care [8], equity issues in elementary computer science education [7], and beyond. Similarly, we have built an AI architecture that supports distributed AI authorship opening up endless possibilities in creating classifiers that respond to text, audio, or chat data to support in-/pre-service teachers to practice and reflect how to respond to issues of equity.

\section{Acknowledgements}

This research was supported by the National Science Foundation under Grant No. 1917668 and the the Bill and Melinda Gates Foundation Learning Engineering Fellowship 


\section{Notes}

1. Teacher Moments Code - https://github.com/mit-teaching-systems-lab/dcss

2. Text Classifier Integration - https://github.com/mit-teaching-systems-lab/dcss-sentimentanalysis-agent

3. Audio Classifier Integration - https://github.com/mit-teaching-systems-lab/dcss-confusionanalysis-agent

4. Conversation Agent Integration - https://github.com/mit-teaching-systems-lab/dcssremote-ai-integration

\section{References}

1. Anderson, N., Slama, R., Moussapour, R., Benoit, G., Reich, J.: Using Digital Clinical Simulations and Authoring Tools to Support Teachers in Eliciting Learners' Mathematical Knowledge. Online (2020)

2. Dutt, R., Hillaire, G., Fang, A., Larke, L., Rosé, C., Reich, J.: Investigating Adoption and Collaboration with Digital Clinical Simulations by Teacher Educators. In: Society for Information Technology \& Teacher Education International Conference. pp. 1209-1217. Publisher: Association for the Advancement of Computing in Education (AACE), Online (Mar 2021), http://www.learntechlib.org/p/219277/

3. Hillaire, G., Larke, L., Reich, J.: Digital Storytelling through Authoring Simulations with Teacher Moments. In: Society for Information Technology \& Teacher Education International Conference. pp. 1736-1745. Publisher: Association for the Advancement of Computing in Education (AACE), Online (Apr 2020)

4. Hillaire, G., Larke, L., Reich, J., Fang, A.: Technology Adoption Concerns and HelpSeeking from Teacher Educators Authoring, Implementing, and Researching Equity Focused Simulations. (Apr 2021)

5. Littenberg-Tobias, J., Reich, J., Borneman, E.: Measuring Equity-Promoting Behaviors in Digital Teaching Simulations: A Topic Modeling Approach. Online (Nov 2020), https://doi.org/10.35542/osf.io/vmbd5

6. Marvez, G.R., Littenberg-Tobias, J., Ortega, T., Breakstone, J., Reich, J.: Measuring Teachers' Civic Online Reasoning in a MOOC with Virtual Simulations and Automated Feedback Systems. In: The Learning Ideas Conference. Online

7. Sheridan, S., Alkhateeb, B., Mouza, C.: Comparing How In-service and Pre-service Teachers Confront Elementary CS Equity Problems of Practice. (Apr 2021)

8. Sullivan, F., Hillaire, G., Larke, L., Reich, J.: Using Teacher Moments during the COVID-19 Pivot. Journal of Technology and Teacher Education 28(2), 303-313 (2020), publisher: Association for the Advancement of Computing in Education

9. Thompson, M., Owho-Ovuakporie, K., Robinson, K., Kim, Y.J., Slama, R., Reich, J.: Teacher Moments: A Digital Simulation for Preservice Teachers to Approximate Parent-Teacher Conversations. Journal of Digital Learning in Teacher Education 35(3), 144-164 (May 2019) 